III. Aus dem Institut für allgemeine Pathologie an der Königl. Universität Bologna, Direktor Prof. Dr. G. Tizzoni.

\title{
Die experimentelle Immunität gegen
} Influenza.

Erste Versuchsreihe.

\section{Von Dr. Alessandro Bruschettini.}

Durch meine früheren Untersuchungen über den Influenzabacillus ${ }^{5}$ ) ist es mir allein von allen Forschern gelungen, auf deutliche, sichere Weise die pathogene Wirkung dieses Mikroorganismus auf Thiere nachzuweisen und ausserdem die Bedingungen festzustellen, unter welchen man bei dem Kaninchen, welches ich als besonders aufnahmefähig für diese Infection und Intoxication nachgewiesen habe, eine bald leichte, vorübergehende, bald schwere, immer tödtliche Krankheitsform hervorrufen kann; auch habe ich bewiesen, dass diese beiden Krankheitsformen nach ihrer klinischen Erscheinung, wie nach ihren anatomischen Charakteren genau den beiden Typen entsprechen, unter denen die Influenza beim Menschen auftritt.

Die Unterschiede, welche die mit lebenden oder filtrirten Culturen injicirten Thiere in Hinsicht auf das klinisch-anatomische Bild darboten, hängen vorzüglich von der Beschaffenheit des Nährbodens $a b$, auf welchem sich die Cultur entwickelt hat, ferner von der angewendeten Menge derselben und endlich von dem Theile, in welchen die Injection gemacht wird.

Während lebende Culturen in Fleischbrühe oder auf Agar selbst wenn sie in die Luftröhre eingespritzt werden, nur eine

5) Ricerche batteriologiche sull' influenza. Arch. per le Sc. mediche Vol. XVI, No. 19. - Nuovo contributo allo studio del bacillo dell' influenza e specialmente della sua azione patogena nel coniglio. Rif. med. 1893 No. $81-83$. 
geringe, vorübergehende Erhöhung der Körpertemperatur hervorbringen, besitzen dagegen diejenigen, welche sich im Blut entwickelt haben, sehr starke pathogene Kraft $^{1}$ ).

Diese Culturen im Blut bringen Eiterung hervor, wenn sie unter die Haut injicirt werden, und nur bisweilen nach mehreren Tagen den Tod durch Marasmus. Dagegen bringen sie acute, kein eigenthümliches klinisches Bild zeigende, aber schnell den Tod verursachende Intoxication hervor, wenn sie in den Kreislauf oder in das Peritoneum injicirt werden. In die Luftröhre eingespritzt, verursachen sie den Tod unter den klinischen Erscheinungen der Influenza, mit den Läsionen der Bronchien und Lungen, welche dieser Krankheit eigenthümlich sind und je nach der Menge des angewendeten Materials mehr oder weniger heftig auftreten.

Was die Dosis der lebenden Cultur in Blut betrifft, welche nöthig ist, um den Tod des Thieres in einer bestimmten Zeit zu veranlassen, so liatte ich durch zahlreiche Experimente festgestellt, dass $0,25 \mathrm{ccm}$ dieser Culturen, in den Kreislauf oder in das Peritoneum eingebracht, das Thier in ungefähr 48 Stunden tödteten, während $0,10 \mathrm{ccm}$ derselben, in die Trachea injicirt, nach $10-12$ Tagen mit Sicherheit dieselbe Wirkung hervorbrachten.

Was die filtrirten Culturen betrifft, so werde ich in einer Arbeit über die von dem Influenzabacillus hervorgebrachte toxische Substanz, welche bald veröffentlicht werden wird, und worïber man eine Andeutung in meinem letzten Aufsatze über diesen Mikroorganismus ${ }^{*}$ ) finden kann, nachweisen, dass die von ihner hervorgebrachten Wirkungen ebenfalls von sehr verschiedener Intensität sind, nicht nur je nach der Dosis und der Stelle der Injection, sondern auch je nach dem Nährboden, auf welchem sich die Cultur entwickelt hat. So bringen Culturen in Fleischbrühe und Blut, nach Filtrirung durch Berkefeld'sche Kerzen, wenn sie unter die Haut, oder in die Bauchhöhle injicirt werden, je nach der eingespritzten Menge entweder eine starke, aber vorübergehende Temperaturerhöhung, oder eine langsame, zum Tode führende Intoxication hervor, welcher immer nach mehreren (25-30) Tagen unter Erscheinungen eines so tiefen Marasmus eintrat, dass das Thier zum Skelet abgemagert war.

Dagegen erzeugen auf dieselbe Weise filtrirte Culturen in Blut, wenn sie ebenso unter die Haut oder in die Bauchhöhle eingespritzt werden, das Bild einer sehr acuten Intoxication, welche iminer nach kurzer Zeit mit dem Tode endigt. Auch in diesem Falle suchte ich die Minimaldosis zu bestimmen, welche in gegebener Zeit zum Tode führt, und fand, dass $0,25 \mathrm{ccm}$ der Cultur, in das Peritoneum injicirt, den Tod des Thieres in ungefähr 36 Stunden herbeiführen, und $4 \mathrm{ccm}$, unter die Haut eingespritzt, in $48-60$ Stunden.

Mit diesen Resultaten besass ich alle nöthigen Elemente, um Experimentaluntersuchungen über die Immunität gegen die Cultur des Influenzabacillus anzustellen.

Ich theilte meine Forschungen über die experimentelle Immunität gegen den Influenzabacillus in drei Abschnitte. In dem ersten suchte ich zu ergünden, ob es möglich sei, Thiere gegen die Culturen dieses Bacillus zu vacciniren, in dem zweiten, ob die durch Vaccination erworbene Immunität durch Injection des Blutes vaccinirter auf andere Thiere übertragen werden könne; endlich in einer dritten Versuchsreihe versuchte ich, ob man mit demselben Blutserum die Krankheit nicht nur verhüten, sondern auch nach ihrem Ausbruche heilen könne.

\section{Vaccinationsversuche gegen die Culturen des} Influenzabacillus.

Alle Vaccinationsversuche wurden an Kaninchen ausgeführt, und zwar durch Einspritzungen steigender Dosen von filtrirten

1) Was die Unterschiede zwischen den von mir und den von Pfeiffer bei den Culturen des Influenzabacillus auf gewöhnlichen Nährböden erhaltenen Resultaten betrifft, so werde ich in einer zunächst zu publicirenden Arbeit nachweisen, dass dieselben a usschliesslich von der Qualität der zur Impfung benutzten Cultur und von der Art und Weise abhängen, wie diese ausgefuhrt wird. So erhält man, wie ich bei meinen ersten, schon publicirten Versuchen nachgewiesen habe, positive Uebertragungen des Bacillus auf Agar, Fleischbruhe und Gelatine für eine oder zwei Generationen, wenn man den Impfstoff einer Cultur in Blut entnimmt und die Uebertragung mit einem sehr dicken Platinhaken verrichtet, und zwar wegen der Hämoglobinmenge, welche zugleich mit dem Bacillus eingefuhrt wird. So klein sie auch ist, genugt sie doch zu der Entwickelung des Bacillus, während Impfungen auf die gewohnlichen, angefuhrten Nährmittel ausgefürt, wenn sie, wie es Pfieiffer thut, von Agar entnommen werden, welches nur oberflächlich mit einem Blutstropfen befeuchtet ist (Blutagar), immer ganz steril bleiben. Die Culturen auf Blut wurden direkt in Kaninchenblut gemacht, welches in sterilisirten Gefässen gesammelt worden war, und von diesem benutzte man für die Uebertragungen oder die Einspritzungen in Thiere das Serum, welches sich von dem Coagulum trennt, und in welchem eine grössere oder geringere Menge von Hämoglobin enthalten war.

2) Nuovo Contributo etc. Rif. med. 1893 No. 81--83.
Culturen in Fleischbrühe und Blut, oder von ebenfalls filtrirten Culturen in reinem Blut, welche, wie wir gesehen haben, viel toxischer sind, als erstere. Von den mit filtrirten Culturen in Fleischbrühe und Blut behandelten Kaninchen wurden einigen nach Beendigung der Reihe der vaccinirenden Injectionen stärkere Einspritzungen von filtrirten Blutculturen gemacht. Diese Thiere zeigten nach jeder der ersten vaccinirenden Einspritzungen eine sehr merkliche Temperaturerhöhung, aber mit dem Fortschreiten der Vaccination verschwand auch dieses Symptom, und von da an zeigten die Thiere, im Gegensatz zu den Controllthieren, nach weiteren Injectionen keine wahrnehmbare Abweichung mehr von ihrem Gesundheitszustande.

Ich berichte hier über ein Beispiel von jeder der von mir befolgten Vaccinationsmethoden.

1. Ein Kaninchen (No. 7), $2010 \mathrm{~g}$ schwer, erhielt im ganzen während ziemlich langer Zeit (72 Tage) $60 \mathrm{ccm}$ filtrirter Cultur in Fleischbrühe mit Blut. Gegen die ersten Injectionen reagirte das Thier durch starke Temperaturerhöhung, welche bis auf $41,3^{0}$ stieg und Abnahme des Körpergewichtes, aber diese Erscheinungen liessen allmählich an Intensität nach, bis sie nach den letzten Injectionen ganz ausblieben.

Zwölf Tage nach der letzten vaccinirenden Einspritzung injicirte man in den Kreislauf zwei Tropfen $(0,10 \mathrm{ccm})$ einer Cultur in Blut des Influenzabacillus. Das Thier zeigte kein einziges krankhaftes Symptom. Nach weiteren 15 Tagen wurde in die Trachea eine weitere Einspritzung von $0,25 \mathrm{ccm}$ Blutcultur gemacht, aber auch hierauf zeigte das Thier nur geringe Temperaturzunahme, welche nach zwei Tagen ganz verschwunden war. Controllkaninchen, welchen dieselben Mengen in den Kreislauf und in die Luftröhre injicirt worden waren, starben am zwölften und neunten Tage.

2. Ein zweites Kaninchen (No. 21), $2400 \mathrm{~g}$ schwer, hatte ebenfalls in 69 Tagen $60 \mathrm{ccm}$ filtrirter Cultur in Fleischbruhe und Blut erhalten, und bekam dann noch in sechs- bis achttägigen Zwischenräumen vier Injectionen unter die Haut von $15 \mathrm{ccm}$ filtrirter Blutcultur in steigenden Dosen von $1,2,4,8 \mathrm{ccm}$. Auch in diesem Falle trat bis zur drittletzten vaccinirenden Injection von Fleischbrühe mit Blut Verminderung des Körpergewichtes und Fieber bis zu einem Maximum von 41,10 ein. Zehn Tage nach der letzten vaccinirenden Injection wurden dem Thiere 0,50 ccm Blutcultur des Influenzabacillus in die Trachea eingespritzt; und es zeigte nur eine leichte vorübergehende Temperaturerhöhung. Die Controllthiere dagegen starben nach einer gleichen Einspritzung nach acht Tagen.

3. Ein drittes Kaninchen endlich (No. 23), $2370 \mathrm{~g}$ schwer, erhielt im ganzen in 42 Tagen $40 \mathrm{ccm}$ filtrirter Blutcultur und zeigte nichts weiter, als die gewöhnliche Temperaturerhöhung nach den ersten Einspritzungen. 10-22 Tage nach der letzten vaccinirenden Injection widerstand dieses Kaninchen ohne die geringste Störung einer Probeinjection von $4 \mathrm{ccm}$ Blutcultur in die Bauchhöhle und von $1 \mathrm{ccm}$ derselben Cultur in die Luftröhre. Mit derselben Menge an denselben Stellen inoculirte Controllkaninchen starben 48 Stunden und vier Tage nach der Injection.

Diese Resultate sind gewiss sehr wichtig, denn sie beweisen, dass man ohne grosse Schwierigkeit dahin gelangen kann, Kaninchen gegen die Culturen des Influenzabacillus zu immunisiren, und dass diese Vaccination nicht nur eine allgemeine, sondern auch eine locale Immunität bewirkt, selbst in den Organen, welche am leichtesten von diesem Virus ergriffen werden, auch wenn die Infection unmittelbar in ihnen stattfindet.

Hierauf wollte ich untersuchen, ob die von mir dargethane Immunität gegen den Influenzabacillus durch eine bacterientödtende Wirkung des Blutes der vaccinirten Thiere, oder durch einfache antitoxische Wirkung dieses Serums zustande komme.

Die hierauf bezüglichen Versuche wurden auf folgende Weise ausgeführt:

Zehn oder zwölf Tage nach der letzten Probeinjection wurde der Carotis der vaccinirten Kaninchen, über welche oben kurz berichtet worden ist, eine gewisse Menge von Blut entnommen, und das Serum nach seiner Abscheidung in sterilisirte Röhren gefüllt. Dann schabte man die Oberfläche einer Cultur von Agar mit Blut $a b$, und machte mit dem erhaltene Materiale eine ziemlich concentrirte Emulsion in sterilisirter Fleischbrühe, und von dieser wurden dann zwei Oesen voll in $0,50 \mathrm{ccm}$ von dem Blutserum der immunisirten Thiere einerseits, und andererseits die gleiche Menge desselben Materials in $0,50 \mathrm{ccm}$ normalen Serums übertragen. Die Röhren wurden in Thermostaten bei $37^{\circ} \mathrm{C}$ gebracht, und nach $1 / 2,1,1,30,2,3,4,5,6,24$ und 72 Stunden Uebertragungen auf Blutagar gemacht. Die Entwickelung der Culturen war in allen Röhren gleich, ohne den geringsten Unterschied gegen die Controllculturen. Bei der Wiederholung des Versuchs, wobei eine einzige Oese der Influenzabacillenemulsion mit $0,50 \mathrm{ccm}$ Serum zusammengebracht wurde, war der Erfolg derselbe. 
Das Blutserum der gegen Influenza immunisirten Thiere übt also keine tödtende Wirkung auf den Bacillus dieser Krankheit aus.

Es blieb also noch übrig, zu untersuchen, ob dieses Serum wenngleich es keine Bacterien tödtende Eigenschaften besass, mit antitoxischer Kraft gegen das von dem Influenzabacillus erzeugte Toxin ausgestattet wäre.

$\mathrm{Zu}$ diesem $\mathrm{Zweck}$ brachte ich in fünf sterilisirte Glasröhren $2,50 \mathrm{ccm}$ filtrirter Blutcultur und fügte zu dreien von ihmen beziehungsweise $0,050,0,25$ und $0,50 \mathrm{ccm}$ von dem Serum des vaccinirten Thieres hinzu. In die vierte Röhre brachte ich dagegen $0,50 \mathrm{ccm}$ normales Blut und liess die fünfte zum Vergleich übrig. Alle diese Röhren wurden bei $37{ }^{\circ} \mathrm{C}$ in den Thermostaten gebracht Nach 24 Stunden wurde ihr Inhalt in das Peritoneum von fünf Kaninchen eingespritzt, welche möglichst dasselbe Gewicht hatten. Diese Versuche wurden mit dem Serum der drei oben erwähnten Kaninchen ausgeführt, nämlich No. 7, 21 und 23.

Die Resultate waren verschieden, je nach dem angewendeten Serum.

Durch das Serum des Kaninchens No. 7, welches mit filtrirter Cultur in Fleischbrühe und Blut vaccinirt worden war, starben 12-14 Stunden nach der Injection, also unter den Symptomen der acuten Vergiftung, die Controllkaninchen und ebenso die mit 2,50 ccm filtrirter Blutcultur inoculirten, welche 24 Stunden lang mit $0,50 \mathrm{ccm}$ normalen Serums und mit $0,050 \mathrm{ccm}$ immunisirenden Serums in Berührung gewesen war. Die anderen beiden Thiere dagegen, welche mit $2,50 \mathrm{ccm}$ flltrirter Blutcultur (welche 2 Stunden lang mit 0,25 und $0,50 \mathrm{ccm}$ von dem Serum des immunisirten Thieres in Berührung gewesen war) inoculirt worden waren, zeigten Fieber und Abnahme des Gewichts und starben an Marasmus am zehnten und ier hnten Tage.

Das BlutserumvonThieren, welchegegendieInfluenza mit filtrirten Culturen in Fleischbrühe und Blutvaccinirt worden sind, ist also nicht fähig, wenigstens in der angewendeten Dosis, das Toxin, welches der Influenzabacillus in Blutculturen bildet, vollständig zu zerstören, vermindert aber seine toxische Kraft, so dass die mit diesem, zum Theil zersetzten Toxin inoculirten Thiere keine acuten Symptome mehr zeigen, und der Tod mit bedeutender Verzögerung nur durch Marasmus eintritt.

Das Kaninchen No. 21, welches mit Culturen in Fleischbrühe und Blut vaccinirt, und dessen Immunität darauf durch Einspritzung filtrirter Blutcultur verstärkt worden war, lieferte ein viel kräftigeres Serum als das vorhergehende. In der That starb nur ein mit $2,50 \mathrm{ccm}$ filtrirter Blutcultur, welche mit $0,050 \mathrm{ccm}$ dieses Serums zusammengestanden hatte, inoculirtes Kaninchen an Marasmus am fünfzehnten Tage, während zwei andere, mit derselben Menge von. Cultur, welche 24 Stunden lang mit 0,25 und $0,50 \mathrm{ccm}$ Serum in Berührung gewesen war, inoculirte Tliere keine andere Krankheitserscheinung zeigten, als eine leichte, vorübergehende Temperaturerhöhung und eine merkliche Gewichtsverminderung; heute befinden sie sich noch am Leben und bei guter Gesundheit, einen Monat nach dem Experimente. Die Controllthiere dagegen, denen dieselbe Menge filtrirter Blutcultur in die Bauchhöhle injicirt worden war, starben nach 12-14 Stunden.

Die Injectionen von filtrirter Blutcultur, a usgeführt nhieren, welche schon durch filtrirte Culturen in Fleischbrühe und Blut immungeworden sind, sind also imstande, die immunisirende Kraft ihres Serums bedeutend zu erhöhen, so dass dieses fähig wird, in vitro die Wirkung des Toxins des Influenzabacillus fast ganz zu zerstören.

Noch wirksamer zeigte sich in vitro das Serum derjenigen Thiere, welche mit starken Mengen filtrirter Blutculturen vaccinirt worden waren. In der That zeigten die Thiere, welchen $2,50 \mathrm{ccm}$ filtrirter Blutcultur, welche 24. Stunden lang mit $0,050,0,25$ und $0,50 \mathrm{ccm}$ von dem Serum des Kaninchens No. 23 in Berührung gewesen war, injicirt. wurde, kein einziges Krankheitssymptom; sie befinden sich noch am Leben und in vortrefflichem Zustande, 25 Tage nach der Injection, während die Controllthiere nach der gewöhnlichen Zeit von 12-14 :Stunden starben.

Das Blutserum mit filtrirter Blutcultur vaccinirter Thiere zerstört also a ch in kleinster Menge in vitrodie Wirkung der toxischen Producte des Influenzabacillus.

Aus dem bis jetzt gesagten folgt also, dassdas Blutserum eines gegen Influenza vaccinirten Thieres in vitro sehr bedeutende antitoxische Kraft besitzt, dass aber diese Kraft sehr verschieden. ist, nicht nur nach der Menge des zum Zwecke der Vaccination injicirten Materials, sondern auch nach seiner Qualität.

So ist also das Serum von Thieren, die mit Culturen in Fleischbrühe und Blut vaccinirt wurden, weniger kräftig; als das- jenige, welches Thieren entnommen wurde, welche mit denselben Culturen und danu noch mit filtrirten Blutculturen geimpft worden sind, und dieses wieder schwächer als das von Kaninchen, welche nur mit starken Mengen von Blutcultur vaccinirt wurden. Dies wird dadurch bewiesen, dass unter gleichen Umständen das erstere Serum die in den Filtraten der Blutculturen enthaltenen toxischen Stoffe in vitro nicht $\mathrm{zu}$ neutralisiren vermag, die zweiten dagegen, besonders das letztere, diese Wirkung vollständig erreichen. Auf ähnliche Weise gelingt es, mit dem Serum in geringerem Grade immunisirter Thiere, also solcher, welche mit filtrirten Culturen in Fleischbrühe und Blut vaccinirt wurden, in vitro die Wirkung einer gewissen Menge filtrirter Cultur in Fleischbrühe und Blut zu neutralisiren, aber es gelingt nicht, eine gleiche Dose von Blutcultur unwirksam zu machen, eben weil, wie wir gesehen haben, die zweite viel toxischer ist als die erste.

In der That widerstanden von drei Thieren, welche zu gleicher Zeit inoculirt wurden, und zwar zwei mit einer filtrirten Cultur in Fleischbrühe und Blut, und das dritte mit einer filtrirten Blutcultur, welche mit $0,25 \mathrm{ccm}$ von dem Serum des Kaninchens No. 7 in Berührung gewesen war, die beiden ersten der Injection und leben noch jetzt, während das letztere an langsamer Intoxication nach acht Tagen starb.

II. Versuche über die Uebertragung der Immunität von einem Thier auf das andere durch Blutserum.

Die unternommenen Experimente hatten den doppelten Zweck, die immunisirende Wirkung des Blutserums gegen eine Infection und gegen eine Intoxication festzustellen.

Da ich beobachtet hatte, dass das Blutserum der mit filtrirten Culturen in Fleischbrühe und Blut vaccinirten Thiere in vitro begrenzte antitoxische Kraft besass, so beschränkte ich bei diesen Versuchen über die schützende Wirkung des Serums meine Untersuchungen auf das Blut derjenigen Thiere, welche mit filtrirten Blutculturen geimpft worden waren

Die Schutzimpfungen wurden immer in die Bauchhöhle gemacht, und die darauf folgenden Probeinfectionen bald in den Kreislauf, bald in die Luftröhre.

A. Immunisirende Schutzwirkung des Blutserums gegen eine Intoxication.

1. Einem $1650 \mathrm{~g}$ schweren Kaninchen (No.61) werden in das Peritoneum $5 \mathrm{ccm}$ Blutserum von einem gegen Influenza durch $40 \mathrm{ccm}$ filtrirter Blutcultur vaccinirten Kaninchen eingespritzt. Temperatur im Augenblick der Injection $39,2^{\circ} \mathrm{C}$. Nach 24 Stunden Einspritzung von $0,25 \mathrm{ccm}$ filtrirter Blutcultur in die Jugularis. Die Temperatur schwankt zwischen $39,2^{\circ}$ und $39,6^{\circ}$, das Gewich bleibt unverändert, und jetzt, nach 18 Tagen, befindet sich das Thier vollkommen wohl. Ein Controllkaninchen dagegen, welchem in die Jugularis $0,25 \mathrm{~cm}$ filtrirter Blutcultur injicirt worden waren und welches im Augenblick der Injection eine Temperatur von $39,6^{\circ}$ besass, zeigte sechs Stunden nach der Injection eine Erhöhung derselben bis auf $40,2^{0}$ und starb 42 Stunden nach der Operation.

Das angewendete Blutserum zeigte also eine immunisirende Kraft wie $1: 330$.

2. Einem $1440 \mathrm{~g}$ wiegendenden Kaninchen wird in das Peritoneum $1 \mathrm{ccm}$ von dem Serum desselben Kaninchens, wie bei No. 61 eingespritzt, und 24 Stunden nachher (Temperatur $39^{\circ}$ ) in die Jugularis $0,25 \mathrm{ccm}$ filtrirter Blutcultur. Das Gewicht und die Temperatur bleiben unverändert, und das Thier lebt noch nach 18 Tagen, während das Controllthier nach 38 Stunden starb.

Kraft des Serums wie $1: 1500$.

3. Einem $1740 \mathrm{~g}$ schweren Kaninchen (No. 63) werden in das Peritoneum $0,10 \mathrm{ccm}$ Blutserum von dem gewölnnlichen Kaninchen, und 24 Stunden später (Temperatur $39,5^{\circ}$ ) in die Jugularis $0,25 \mathrm{cem}$ filtrirte Blutcultur eingespritzt. Temperatur und Gewicht bleiben normal: das Controllthier stirbt nach 40 Stunden.

Kraft des Serums wie $1: 17400$

4. Einem $1800 \mathrm{~g}$ schweren Kaninchen (No.69) werden in das Peritoneum $0,05 \mathrm{~cm}$ von dem Blutserum des immunisirten Kaninchens, und 24 Stunden später (Temperatur $39,4^{\circ}$ ) in die Jugularis $0,25 \mathrm{ccm}$ filtrirte Blutcultur injicirt. Das Thier leidet. durchaus nicht, während das Controllthier nach 34 Stunden stirbt.

Kraft des Serums wie $1: 36000$.

B. Immunisirende Schutzwirkung des Blutserums gegen eine Infection.

1. Einem $1830 \mathrm{~g}$ schweren Kaninchen (No. 67) wird in das Peritoneum $1 \mathrm{ccm}$ von dem Serum eines immunisirten Kaninchens, und 24 Stunden später (Temperatur $39,70^{\circ}$ in die Trachea $0,25 \mathrm{ccm}$ einer virulenten Blutcultur eingespritzt. Das Thier zeigt keine bemerkenswerthen Erscheinungen; das Controllthier stirbt am fünften Tage. 
Kraft des Serums wie $1: 18300$.

2. Einem $2100 \mathrm{~g}$ schweren Kaninchen (No. 68) werden in das Peritoneum $0,05 \mathrm{ccm}$ von dem Serum eines immunisirten Kaninchens und 24 Stunden später (Temperatur $39,1^{\circ}$ ) in die Luftröhre $0,25 \mathrm{ccm}$ virulenter Blutcultur injicirt. Man bemerkt nichts weiter, als eine geringe, vorübergehende Temperaturerhöhung, während das Controllthier am fünften Tage stirbt.

Kraft des Serums wie 1:42000.

Das Blutserum der durch filtrirte Bluteultur gegen Influenza vaccinirten Thiere vermag also auch in sehr schwachen Dosen anderen Kaninchen die Immunitat sowohl gegen eine Infection, als gegen eine Intoxication zu übertragen, und nach den gemachten Versuchen beträgt das Maximum der immunisirenden Kraft des Serums meiner Thiere, soweit es bis jetzt untersucht worden ist, $1: 36000$ und $1: 42000$, ohne Unterschied, ob dieses Serum gegen die Infection oder gegen die Intoxication angewendet wurde, welche durch das Toxin des Influenzabacillus erzeugt worden war. Dies bestätigt die Annahme, dass die verderblichen Wirkungen dieses Bacillus auf den Organismus weniger durch die Gegenwart dieses Mikrobiums selbst, als durch das von ihm hervorgebrachte Toxin verursacht werden.

Später werde ich bekannt machen, welches der höchste Grad von Immunität ist, welchen das Blutserum der gegen die Culturen des Influenzabacillus vaccinirten Thiere erreichen kann, und dann werde ich auch die Resultate der Experimente von Vaccinationen an grossen Thieren mittheilen, welche ich schon seit einiger Zeit begonnen habe, um das nöthige Material zu sammeln, und zum Versuch der Immunisation und Heilung der Influenza beim Menschen übergehen zu können.

III. Experimente über die Heilung der Influenza durch das Serum vaccinirter Thiere.

Für diese Versuche wählte ich als Typus der Infection denjenigen, welchen man durch Injection von Blutcultur des Influenzabacillus in die Trachea erhält, weil die in diesem Theile ausgeführten Injectionen an Thieren das Bild der Krankheit am treuesten darstellen.

Ein $1600 \mathrm{~g}$ schweres Kaninchen (No. 66) wird am 11. Juni 1893 um $11 \mathrm{Uhr}$ morgens mit $0,25 \mathrm{ccm}$ Blutcultur in die Luftröhre inoculirt. Temperatur 39,7 0. Zu gleicher Zeit wird ein anderes, $1560 \mathrm{~g}$ schweres Controllkaninchen (Temp. 39,6 ${ }^{\circ}$ ) mit derselben Menge der Cultur inoculirt. Hier folgen die Aufzeichnungen, welche den Verlauf der Krankheit angeben.

\begin{tabular}{|c|c|}
\hline \hline Kaninchen No. 66. & Controllthier. \\
\hline
\end{tabular}

11. Juni $1893,11 \mathrm{Uhr}$ vorm., Temp. $39,7^{0}$,

Gewicht $1600 \mathrm{~g}$. Infection in die Trachea mit $0,25 \mathrm{ccm}$ Blutcultur.

12. Juni, 2 Uhr nachm., Temp. $40,5^{\circ} \mathrm{C}$. Subcutane Injection von $\mathbf{2} \mathrm{ccm}$ des Serums eines immunisirten Kaninchens.

4 Uhr nachm. Temp. $39,5^{\circ}$.

$6 \mathrm{Uhr}$ nachm. Temp. 39,20

13. Juni, 10 Uhr vorm., Temp. $40^{\circ} \mathrm{C}$ Gewicht $1600 \mathrm{~g}$

2 Uhr nachm. Temp. $41,3^{\circ}$. Injection von $3 \mathrm{ccm}$ desselben Serums.

4 Uhr 30 Min. nachm. Temp. 39,4 0 5 Uhr 30 Min. nachm. Temp. 39,6 ${ }^{\circ}$.

6 Uhr nachm. Temp. 39,50 .

14. Juni, 10 Uhr vorm., Temp. $39,0^{\circ}$ Gewicht $1630 \mathrm{~g}$

2 Uhr 30 Min. nachm. Temp. 40,8 ${ }^{\circ}$. Injection von $3 \mathrm{ccm}$ desselben Serums.

3 Uhr 30 Min. nachm. Temp. 39,2

5 Uhr 30 Min. nachm. Temp. $39^{\circ}$.

15. Juni, 10 vorm., Temp. $39,8^{\circ}$

2 Uhr nachm. Temp. 39,6 ${ }^{\circ}$.

4 Uhr nachm. Temp. 39,10.

16. Juni, 10 Uhr vorm., Temp. $39,2^{\circ}$ Die Injectionen werden weggelassen und das Thier bleibt gesund.

Temp. 39, $6^{\circ} \mathrm{C}$, Gewicht $1560 \mathrm{~g}$. Infection in die Trachea mit $0,25 \mathrm{ccm}$ Blutcultur.

Temp. $40,8^{\circ} \mathrm{C}$.

Temp. 41,2 0.

Temp. $40,9^{\circ}$

Temp. 41,1 $0^{\circ}$, Gewicht $1560 \mathrm{~g}$.

Temp. 410.

Temp. 40,90.

Temp. 40,90

Temp. 41,10

Temp. 40,6 0, Gewicht $1470 \mathrm{~g}$.

Temp. $40,5^{\circ}$.

Temp. 40,80

Temp. 40,20

Temp. $40^{\circ}$

Temp. $400^{\circ}$.

Temp. 38,2 o

Der Tod ist erfolgt. Bei der Section findet sich Bronchitis, vielfache Heerde von lobulärer Pneumonie, besonders in der rechten Lunge; fibrinopurulente Pleuritis.

Zweites Experiment.

Kaninchen No. 73.

15. Juni $1893,11 \mathrm{Uhr}$ vorm., Temp. $39,9^{\circ}$ Gewicht 1470 g. Einspritzung von $0,25 \mathrm{ccm}$ Blutcultur in die Trachea.

16. Juni, 10 Uhr vorm., Temp. $39,9^{\circ}$. 12 Uhr vorm. Temp. $39,8^{\circ}$.

4 Uhr nachm. Temp. $40,2^{\circ}$

6 Uhr nachm. Temp. 40,4
Controllthier.

Iemp. 390 , Gewicht $1410 \mathrm{~g}$. Einspritzung von $0,25 \mathrm{ccm}$ Blutcultur in die Trachea.

Temp. 400.

Temp. 40,10.

Temp. $40^{\circ}$.

Temp. 40,60

\section{Kaninchen No. 73.}

17. Juni, 10 Uhr vorm., Temp. 40,9 0 . Subcutane Einspritzung von $3 \mathrm{ccm}$ Serum eines immunisirten Kaninchens. 11 Uhr 30 Min. Temp. $39^{\circ}$ 2 Uhr nachm. Temp. $39,20$. 4 Uhr nachm. Temp. $39,3^{\circ}$

6 Uhr nachm. Temp. $39,6^{\circ}$.

18. Juni, $10 \mathrm{Uhr}$ vorm., Temp. $41^{\circ}$. Injection von $3 \mathrm{ccm}$ desselhen Serums. $11 \mathrm{Uhr}$ vorm. Temp. $39,4^{0}$ 12 Uhr Temp. 39,9 0 .

4 Uhr nachm. Temp. $39^{\circ}$.

19. Juni, $10 \mathrm{Uhr}$ vorm., Temp. $39,2^{\circ}$ Die heilenden Injectionen hören auf und das Thier bleibt gesund.

Aus den beiden hier vorgeführten Versuchen sieht man also, dass das Blutserum gegen Influenza vaccinirter Thiere starke Heilkraft besitzt und selbst in ziemlich geringer Menge $(6 \mathrm{ccm})$ das Thier von einer so schweren Infection zu heilen vermag, dass sie in 5-6 Tagen den Tod bringt, selbst wenn die Behandlung erst 48 Stunden nach der Einspritzung beginnt, wenn nämlich das Thier schon deutliche Symptome der Krankheit darbietet, was sich vorzüglich durch die Erhöhung der Körpertemperatur ausspricht. Es scheint nun bemerkenswerth, dass die erste Wirkung des heilenden Serums bei den mit Culturen des Influenzabacillus inficirten Thieren antipyretisch ist. Man begreift, dass, wenn die Temperaturerhöhung in der Influenza eine Wirkung des vom Bacillus dieser Krankheit hervorgebrachten Toxins ist, wie es die Erfahrung beweist, die Neutralisation dieses Toxins durch das Serum vaccinirter Thiere die Temperatur herabsetzen muss. Diese Temperaturerniedrigung kann uns sogar als Anzeichen für den Eintritt der Wirkung des Heilserums dienen.

Aus meinen Versuchen folgt also:

1. Dass das Kaninchen ohne grosse Schwierigkeit gegen die Culturen des Influenzabacillus vaccinirt werden kann.

2. Dass das beste Material, welches den höchsten Grad von Immunität verschafft, durch Blutculturen geliefert wird, welche durch Berkefeld'sche Kerzen filtrirt worden sind.

3. Dass für diese Vaccination das Serum immunisirter Thiere nicht eine die Bacterien tödtende, sondern eine starke antitoxische Kraft besitzt.

4. Dass das Serum vaccinirter Thiere die Eigenschaft besitzt, anderen Thieren die ImmunitatgegendieInfection und die Intoxication durch den Influenzabacillus zu übertragen, und zwar in so hohem Grade, dass das Verhältniss des Serums gegen ein Gramm des Körpergewichts $1 / 42000$, und vielleicht noch viel weniger beträgt.

5. Endlich dass dieses Serum auch eineausgesprochene Heilwirkung besitzt, indem es die Temperatur herabsetzt und Kaninchen vom Tode errettet, bei denen 48 Stunden vorher die schwerste Form der Infection eingewirkt hatte, nämlich die, welche man durch directe Injection der Cultur des Bacillus in die Trachea ausführt, und welche die Controllthiere in wenig Tagen tödtet.

Ich verweile nicht bei der Besprechung der Wichtigkeit dieser Resultate, welche nicht nur den Mechanismus aus einer neuen Infection erläutern und die Zahl der Krankheiten vermehren, bei welchen die modernen Ansichten über die Immunität anwendbar sind, sondern die Hoffnung wecken, dass auch gegen diese Infection die Serotherapie eine nützliche Anwendung finden kann.

Auch wenn die Heilwirkung beim Menschen nicht ihre volle Kraft äusserte, so würden diese Untersuchungen für die Praxis nicht weniger wichtig sein, weil in der Influenza, wie in der Diphtheritis und in allen jenen Krankheiten, welche viele Personen zugleich ergreifen, aber verhältnissmässig kurze Zeit dauern, die Schutzimpfungen mit diesem Serum bei Epidemieen von grossem Nutzen sein können.

Wer auch nur aus Untersuchungen bei Experimenten die Zerstörungen kennt, welche die Influenza (welche gewöhnlich für eine unbedeutende Krankheit gilt) in dem Respirationsapparate hervorbringen kann, wird sicher die Vortheile, welche die Untersuchungen der Praxis bringen können, hoch anschlagen. 